\title{
A BATCH PREPARATION METHOD FOR GRAPHITE TARGETS WITH LOW BACKGROUND FOR AMS ${ }^{14} \mathrm{C}$ MEASUREMENTS
}

\author{
HIROYUKI KITAGAWA ${ }^{1,2}$, TOSHIYUKI MASUZAWA ${ }^{1}$, TOSHIO MAKAMURA ${ }^{3}$ \\ and EIJI MATSUMOTO ${ }^{1}$
}

\begin{abstract}
We have developed a method of graphitization from $\mathrm{CO}_{2}$ samples for accurate ${ }^{14} \mathrm{C}$ measurements by accelerator mass spectrometry. Our batch method, using a sealed Vycor tube, reduces the risk of contamination during graphitization and makes it possible to prepare many samples in a short time (typically 20 samples per day).
\end{abstract}

\section{INTRODUCTION}

For accurate ${ }^{14} \mathrm{C}$ age determination by accelerator mass spectrometry (AMS), initial materials are usually transformed to solid-state carbon, such as graphite, which delivers an intense, long-lasting ion beam (Lowe 1984; Andree et al.1984; Vogel et al. 1984). The contamination of modern carbon during the procedure must be minimized and reproducible.

In our target preparation method, we reduced the $\mathrm{CO}_{2}$ samples catalytically to graphite on $\mathrm{Fe}$ powder in the presence of $\mathrm{H}_{2}$ gas by modifying the method of Vogel et al. (1984). The most important modification involves graphite production by a batch method using a sealed Vycor tube. This reduces the risk of modern carbon contamination and memory effect during graphitization (Vogel, Nelson \& Southon 1987; Gurfinkel 1987), and also allows preparation of many samples in a short time (typically 20 samples per day).

We also describe details of the target-preparation method involving carbon isotopic fractionation during graphitization, yield of graphite from $\mathrm{CO}_{2}$, ion-beam intensity of the target, and background (or blank) level estimated using bituminous coal.

\section{METHODS AND MATERIALS}

The $\mathrm{CO}_{2}$ sample gas is reduced to graphite on Fe powder in a sealed Vycor tube. The reaction is expressed as

$$
\begin{gathered}
\text { Fe catalyst } \\
\mathrm{CO}_{2}+\underset{2}{2 \mathrm{H}_{2} \rightarrow \mathrm{C}}+2 \mathrm{H}_{2} \mathrm{O} . \\
650^{\circ} \mathrm{C}
\end{gathered}
$$

The catalyst, $99.9 \%$ spherical Fe powder $<325$ mesh $(44 \mathrm{~mm}$ ), was weighted in an inner Vycor cup (4 mm I. D. and $6 \mathrm{~mm} \mathrm{O.} \mathrm{D.,} 10 \mathrm{~mm}$ long). The cup with Fe powder was inserted into an outer Vycor tube (7 mm I. D. and $9 \mathrm{~mm} \mathrm{O.} \mathrm{D.,} \mathrm{length} \mathrm{depending} \mathrm{on} \mathrm{sample} \mathrm{size)} \mathrm{with} \mathrm{a} \mathrm{sealed} \mathrm{end} \mathrm{as}$ a reaction vessel. The inner cup and outer tube were first heated at $1000^{\circ} \mathrm{C}$ for $2 \mathrm{~h}$ to remove possible volatile contamination. The outer Vycor tube, used as the reaction vessel, was connected to a vacuum line via an O-ring stopcock (Young Co., Ltd.) and two Ultra-torr unions (Cajon Co., Ltd.) and then evacuated (Fig. 1). After a high vacuum was attained, $0.5 \mathrm{~atm}(500 \mathrm{kPa})$ of pure $\mathrm{H}_{2}$ was introduced into the tube and the stopcock was closed. The tube was removed from the preparation line and set in a hand-made heater with holes $(12 \mathrm{~mm} \mathrm{I}$. D. and $50 \mathrm{~mm}$ deep). The bot-

\footnotetext{
${ }^{1}$ Water Research Institute, Nagoya University, Nagoya 464-01, Japan

${ }^{2}$ Present address: International Research Center for Japanese Studies, Oeyama-cho, Goryo, Nishikyo-ku, Kyoto 610-11, Japan

${ }^{3}$ Dating and Materials Research Center, Nagoya University, Nagoya 464-01, Japan
} 


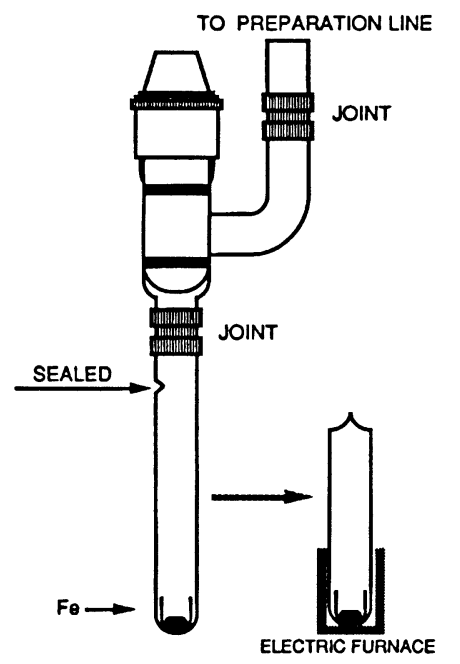

Fig.1. Apparatus design

tom $(c a .2 \mathrm{~cm})$ of the tube was heated at $450^{\circ} \mathrm{C}$ for $1 \mathrm{~h}$ to remove carbon contamination and to reduce the oxidized surface of spherical Fe powder to pure metal. The apparatus was remounted to the vacuum line and evacuated to $<10^{-3}$ torr.

A measured volume of purified $\mathrm{CO}_{2}$ from sample material was cryogenically trapped in the reaction tube. About twice as much pure $\mathrm{H}_{2}$ gas as sample $\mathrm{CO}_{2}$ was added to the volume, and the tube was sealed off with a torch. The bottom $(\mathrm{ca} .2 \mathrm{~cm})$ of the sealed tube with the $\mathrm{CO}_{2}$ sample, $\mathrm{H}_{2}$ and $\mathrm{Fe}$ powder was heated at $650^{\circ} \mathrm{C}$ for $4-6 \mathrm{~h}$. In our laboratory, three reaction tubes can be heated at the same time. As the reaction progresses, liquid $\mathrm{H}_{2} \mathrm{O}$ appears at the upper end of the reaction tube, and $\mathrm{CO}_{2}$ is graphitized onto the $\mathrm{Fe}$ powder. The mixture of graphite and $\mathrm{Fe}$ powder was pressed directly into a 1.5 -mm-diameter hole in an aluminum target holder. The graphite targets were used for ${ }^{14} \mathrm{C}$ measurements with a Tandetron accelerator mass spectrometer (TAMS) at the Dating and Materials Research Center, Nagoya University. Nakai et al. (1984) and Nakamura, Nakai and Ohishi (1987) described our procedure for TAMS ${ }^{14} \mathrm{C}$ measurements.

We investigated isotopic fractionation during graphitization by measuring $\delta^{13} \mathrm{C}$ of $\mathrm{CO}_{2}$ prepared by combustion of the resultant graphite targets using a Finnigan MAT 251 gas ion-source mass spectrometer at the Water Research Institute, Nagoya University. We assessed the level of ${ }^{14} \mathrm{C}$ contamination using different amounts of bituminous coal collected from Yubari Mine, Hokkaido, Japan. The coal, treated by acid-base washing and heated in vacuo to eliminate possible contamination of modern carbon, was combusted to $\mathrm{CO}_{2}$ at $850^{\circ} \mathrm{C}$ in a sealed Vycor tube with $\mathrm{CuO}$, and the $\mathrm{CO}_{2}$ gas was then graphitized as described above.

\section{RESULTS AND DISCUSSION}

\section{Isotopic Fractionation and Yield of Graphite During Graphitization}

We determined the $\delta^{13} \mathrm{C}$ of the initial $\mathrm{CO}_{2}$ sample and resultant graphite, and the yield of graphite from $\mathrm{CO}_{2}$. Graphitization at low yields $(<60 \%)$ was performed by stopping the reaction within 1 $\mathrm{h}$ to measure fractionation. Isotopic fractionation depended strongly on the reaction's progress, and decreased with the increasing yield of graphite from $\mathrm{CO}_{2}$ (Fig. 2). This tendency can be explained by the Rayleigh condensation model of a solid forming from the gas phase in a closed system 


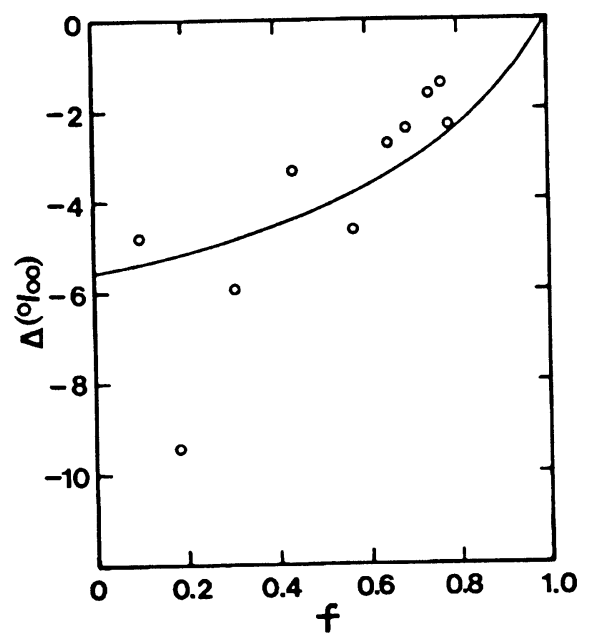

Fig. 2. Isotopic fractionation, $\Delta=\delta^{13} \mathrm{C}$ (graphite) $-\delta^{13} \mathrm{C}$ (initial $\mathrm{CO}_{2}$ ), as a function of the yield, $\mathrm{f}$, of graphite from sample $\mathrm{CO}_{2}$. A least-squares fit of the results for the Rayleigh condensation model is depicted by the solid line.

(Hoefs 1987). At a yield, f, of graphite from $\mathrm{CO}_{2}$, the isotopic fractionation, $\Delta$, is given by

$$
\Delta=\delta s-\delta g=(1-f) / f \varepsilon \ln (1-f)
$$

where $\delta s$ and $\delta g$ are $\delta^{13} \mathrm{C}$ values of the initial $\mathrm{CO}_{2}$ sample and resultant graphite, respectively, and $\varepsilon$ is the carbon isotopic enrichment factor. Regression analysis of 10 data points using Eq. (2) (Fig. 2) gives an $\varepsilon$ of $-5.0 \pm 1.3(1 \sigma)$. The solid line of Figure 2 shows the isotopic fractionation vs. f.

We estimated graphite yield from a $\mathrm{CO}_{2}$ sample for different conditions using the experimental correlation between the yield of graphite from a $\mathrm{CO}_{2}$ sample and isotopic fractionation. The extent of isotopic fractionation between a $\mathrm{CO}_{2}$ sample and resultant graphite depended on the initial pressure of $\mathrm{CO}_{2}$ in the reaction vessel (Fig. 3). We expected a high yield of graphite with a high initial pressure of $\mathrm{CO}_{2}$ in the reaction vessel. Therefore, we changed the tube length of reaction vessel depending on sample size; to prepare ultra-small samples $(<200 \mu \mathrm{g})$, graphitization should be performed at a high initial pressure of $\mathrm{CO}_{2}$ using an extremely small vessel (4 $\mathrm{mm} \mathrm{I}$. D. and $10 \mathrm{~cm}$ long).

\section{${ }^{14} \mathrm{C}$ Background (or Blank) Levels}

Figure 4 shows the results of ${ }^{14} \mathrm{C}$ measurements on graphite targets prepared from ${ }^{14} \mathrm{C}$-free material (Miocene bituminous coal from the Yubari Mine). These targets were prepared during the preparation of other samples with various ${ }^{14} \mathrm{C}$ activities. The average ${ }^{14} \mathrm{C}$ background level for graphitized targets with $>200 \mu \mathrm{g}$ carbon, including the ${ }^{14} \mathrm{C}$ background from TAMS measurements, combustion and graphitization, was $0.112 \pm 0.057$ percent modern carbon (pMC), which corresponds to an equivalent age of $\mathrm{ca} .55 \mathrm{ka} \mathrm{BP}$. This ${ }^{14} \mathrm{C}$ background value is somewhat higher than that of the TAMS system background (0.03 pMC or ca. 65 ka BP; Nakamura \& Nakai 1992; Nakamura, Oka \& Sakamoto 1992) and does not vary with sample size. This difference might be due to a slight residual contamination of the bituminous coal through the cleaning procedure. Our pretreatment procedure before combustion may not be adequate for the bituminous coal. On the other hand, two measurements of targets with $<200 \mu \mathrm{g}$ carbon showed somewhat higher ${ }^{14} \mathrm{C}$ concentrations. The ${ }^{14} \mathrm{C}$ background level tends to increase with decreasing sample size, as reported by Vogel, Nelson and Southon (1987). It seems to be that the increase of ${ }^{14} \mathrm{C}$ background with de- 


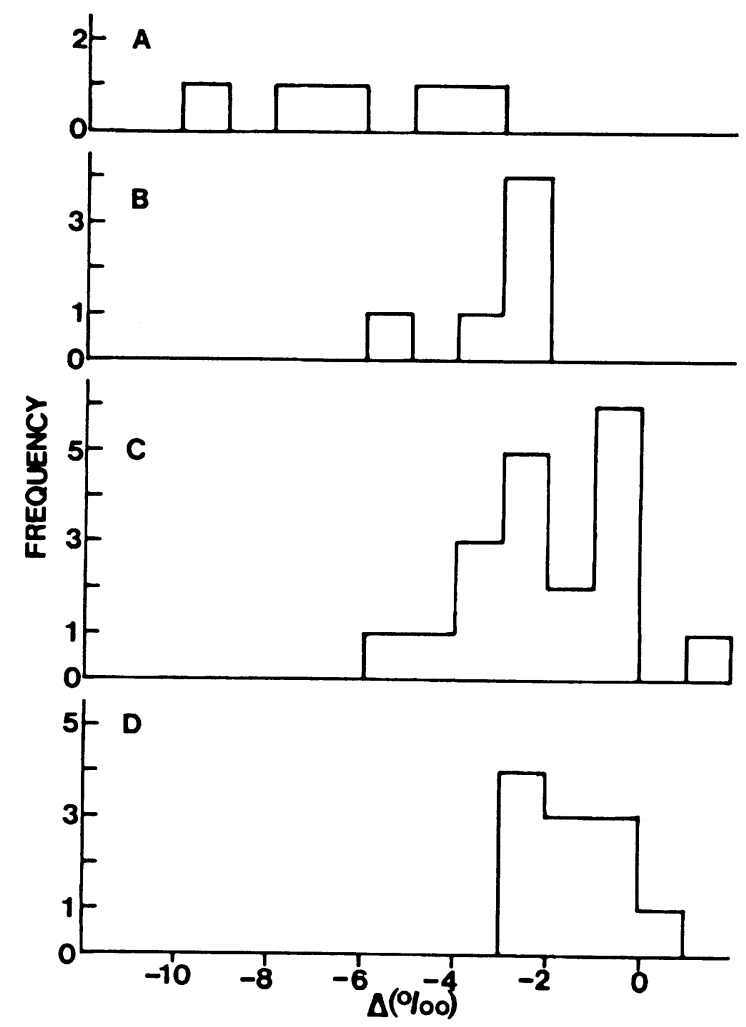

Fig. 3. Isotopic fractionation with different pressures of initial $\mathrm{CO}_{2}$. A. $<100 \mathrm{~mm} \mathrm{Hg}$; B. $100-150 \mathrm{~mm} \mathrm{Hg}$; C. 150-200 mm Hg; D. $>200$ $\mathrm{mm} \mathrm{Hg}$

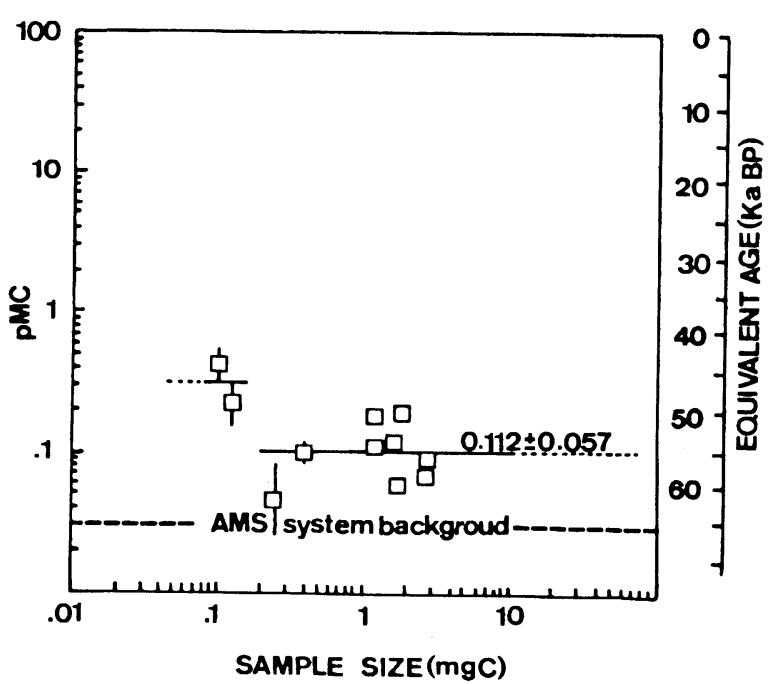

Fig. 4. Results of ${ }^{14} \mathrm{C}$ measurements on graphite prepared from Miocene bituminous coal from the Yubari Mine 
creasing sample size is due to the addition of a constant contamination during the reduction or combustion process, which was not determined precisely.

\section{${ }^{13} \mathrm{C}^{3+}$ Ion-Beam Intensity from Graphitized Target}

The ${ }^{13} \mathrm{C}^{3+}$ ion-beam intensity from a graphitized target is expressed as the average intensity ratio, Is/Ig, of the ${ }^{13} \mathrm{C}^{3+}$ ion-beam intensity of a graphitized target $v s$. that from spectroscopic pure graphite because the ${ }^{13} \mathrm{C}^{3+}$ ion-beam intensity from targets was changed by the geometry and ion source condition of the TAMS system. Is/Ig depends strongly on the $\mathrm{C} / \mathrm{Fe}$ weight ratio (Fig. 5).
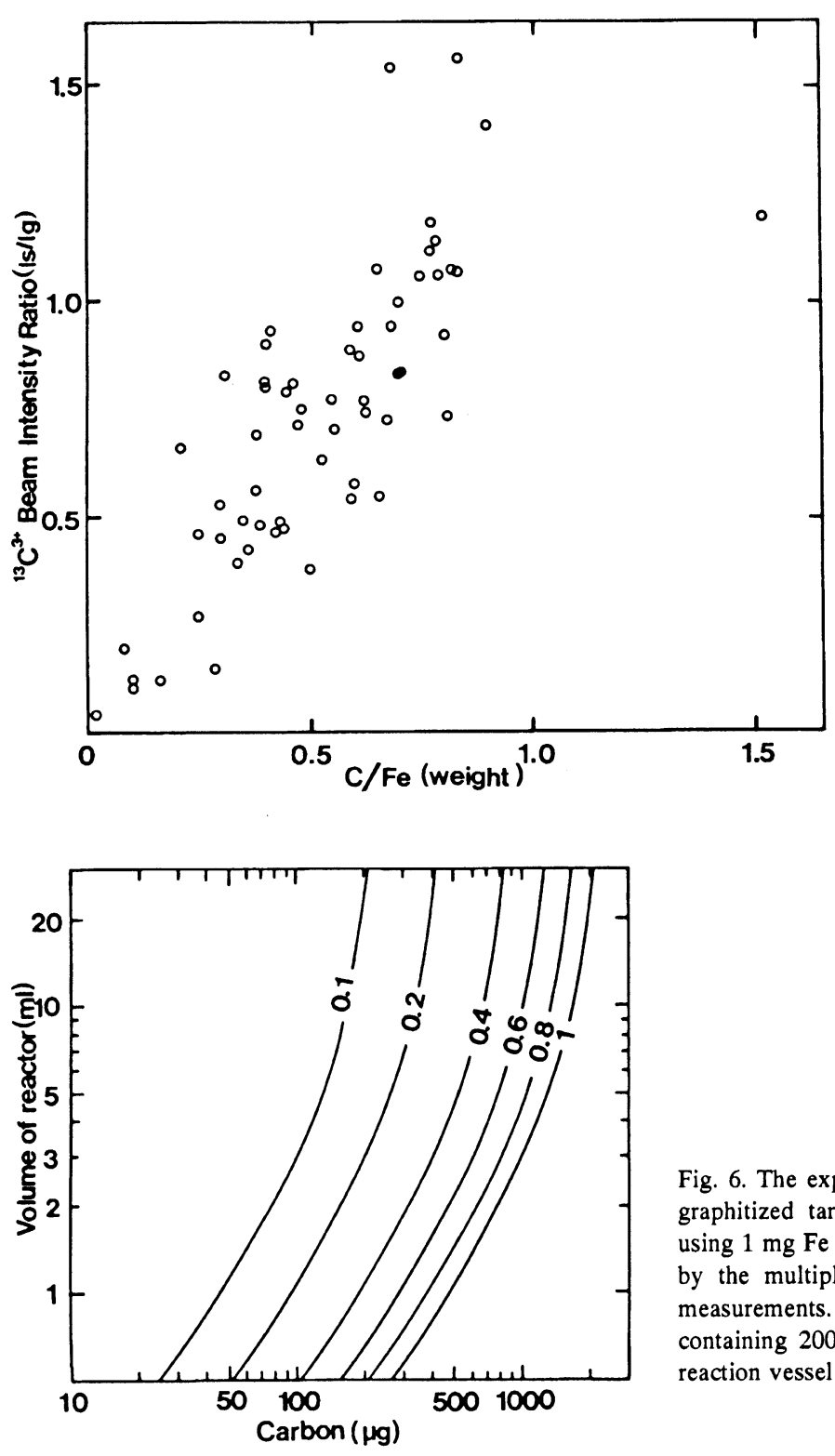

Fig. 5. The ${ }^{13} \mathrm{C}^{3+}$ ion-beam intensity ratio from graphitized targets to the spectroscopic graphite (Is/Ig) as a function of $\mathrm{C} / \mathrm{Fe}$ weight ratio
Fig. 6. The expected ${ }^{13} \mathrm{C}^{3+}$ ion-beam intensity ratio from graphitized targets to the spectroscopic pure graphite, using $1 \mathrm{mg} \mathrm{Fe}$ powder, deduced from a formula obtained by the multiple regression analysis of $78{ }^{14} \mathrm{C}$ TAMS measurements. For example, the Is/ $/ g$ ratio from the target containing $200 \mu \mathrm{g}$ carbon prepared using $1 \mathrm{ml}$ volume reaction vessel is 0.5 . 
The ${ }^{13} \mathrm{C}^{3+}$ ion-beam intensity from targets with a high $\mathrm{C} / \mathrm{Fe}$ weight ratio was higher than that from the spectroscopic graphite. ${ }^{13} \mathrm{C}^{3+}$ ion-beam intensity of the target with a high $\mathrm{C} / \mathrm{Fe}$ weight ratio $(\mathrm{C} / \mathrm{Fe}=1.0)$ was typically $100 \mathrm{nA}$, and ${ }^{14} \mathrm{C}$ counting ratio of up to $15 \mathrm{cps}$ was achieved for a graphitized target from a modern sample. On the other hand, a target with a low $\mathrm{C} / \mathrm{Fe}$ weight ratio showed a low ion-beam intensity; thus, measurement precision worsens. In our TAMS system, we need a minimum of $1 \mathrm{mg}$ of $\mathrm{Fe}$ powder for target preparation so that the measurement precision depends on sample size.

We obtained a formula by the multiple regression analysis of 78 TAMS ${ }^{14} \mathrm{C}$ measurements of graphitized targets. We deduced the expected Is/Ig ratios for these graphitized targets, using $1 \mathrm{mg}$ $\mathrm{Fe}$ powder, from graphitization conditions, their carbon contents, and volumes of the reaction vessels, which correlate with the initial pressure of $\mathrm{CO}_{2}$. Figure 6 shows that when the graphitization is performed in a reaction vessel of $1-\mathrm{ml}$ volume, the ion-beam intensity of a target with $>200 \mu \mathrm{g}$ carbon is $>1 / 2$ the beam intensity of spectroscopic graphite. This also indicates that samples with $200 \mu \mathrm{g}$ carbon are sufficient to date Holocene materials with a precision $200 \mathrm{yr}$ in routine analysis. However, ultra-small samples containing $<200 \mu \mathrm{g}$ carbon have significantly lower ion-beam intensities than those with $>200 \mu \mathrm{g}$ carbon. The precision of the determined age is limited by the ion-beam intensity of targets.

\section{CONCLUSIONS}

We were able to determine the ${ }^{14} \mathrm{C}$ ages of ultra-small samples and extremely old samples by the batch graphitization method in a sealed Vycor tube. The transformation of $\mathrm{CO}_{2}$ samples to graphite targets is rapid and simple and does not require special and expensive apparatus.

\section{REFERENCES}

Andree, M., Beer, J., Oeschger, H., Bonani, G., Hafmann, H. J., Morenzoni, E., Nessi, M., Suter, M. and Wolfi, W. 1984 Target preparation for milligram-size ${ }^{14} \mathrm{C}$ samples and data evaluation for AMS measurements. In Wölfli, W., Polach, H. A. and Anderson, H. H., eds., Proceedings of the 3rd International Symposium on Accelerator Mass Spectrometry. Nuclear Instruments and Methods in Physics Research 233 (B5): 274-279.

Gurfinkel, D. M. 1987 An assessment of laboratory contamination at the Isotrace Radiocarbon Facility. Radiocarbon 29(3): 335-346.

Hoefs, J. 1987 Stable Isotope Geochemistry. Berlin, Spring-er-Verlag: $241 \mathrm{p}$.

Lowe, D. C. 1984 Preparation of graphite targets for radiocarbon dating by Tandetron accelerator mass spectrometer (TAMS). International Journal of Applied Radiation and Isotopes 35: 349-359.

Nakai, N., Nakamura, T., Kimura, M., Sakase, T., Sato, S. and Sakai, A. 1984 Accelerator mass spectrometry of ${ }^{14} \mathrm{C}$ at Nagoya University. In Wölfli, W., Polach, H. A. and Anderson, H. H., eds., Proceedings of the 3rd International Symposium on Accelerator Mass Spectrometry. Nuclear Instruments and Methods in Physics Research 233(B5): 171-174.

Nakamura, T., Nakai, N. and Ohishi, S. 1987 Tech- niques of tandem accelerator mass spectrometry and their applications to ${ }^{14} \mathrm{C}$ measurements. In Gove, $\mathrm{H}$. E., Litherland, A. E. and Elmore, D., eds., Proceedings of the 4th International Symposium on Accelerator Mass Spectrometry. Nuclear Instruments and Methods in Physics Research B29: 335-360.

Nakamura, T., Oka, S. and Sakamoto, T. 1992 Radiocarbon ages of charred wood from the Tokyo pumice flow deposit measured with the Tandetron accelerator mass spectrometer. Journal of Geological Science, Japan 98(9): 908-908 (in Japanese).

Nakamura, T. and Nakai, N. 1992 A Study on older radiocarbon age measurable with accelerator mass spectrometer. Proceedings of the 29th International Geological Congress, Kyoto, Japan: 632.

Vogel, J. S., Southon, J. R., Nelson, D. E. and Brown T. A. 1984 Performance of catalytically condensed carbon for use in accelerator mass spectrometry. In Wölfli, W., Polach, H. A. and Anderson, H. H., eds., Proceedings of the 3rd International Symposium on Accelerator Mass Spectrometry. Nuclear Instruments and Methods in Physics Research 233 (B5): 289293.

Vogel, J. S., Nelson, D. E. and Southon, J. R. $1987{ }^{14} \mathrm{C}$ background levels in an accelerator mass spectrometry system. Radiocarbon 29(3): 323-333. 